\title{
BRASIL IMPÉRIO: PROCESSO DE INDEPENDÊNCIA DO BRASIL
}

\author{
EMPIRE BRAZIL: BRAZILIAN INDEPENDENCE PROCESS \\ Cintia Adriana Sikora \\ Janete Aparecida Guidi
}

RESUMO: O tema que será apresentado nesse artigo é o Brasil Império e o processo de Independência do Brasil, presente estudo teve por objetivo a analisar todo o contexto histórico e o processo de independência do Brasil, mostrando como era o Brasil império, suas características e quando, porque e como ocorreu o processo de independência. A metodologia baseou -se em uma pesquisa bibliográfica exploratória onde será explorado em livros, artigos científicos, sites e teses. E os resultados obtidos nesse artigo é aprendizagem sobre o tema, mostrando o que foi o Brasil império, suas características, quem foi as pessoas importantes dessa época e de que forma ocorreu o processo de independência do Brasil e suas características.

Palavras-chave: Brasil. Império. Independência.

ABSTRACT: The theme that will be presented in this article is the Brazil Empire and the process of Independence in Brazil, this study aimed to analyze the entire historical context and the process of independence in Brazil, showing how Brazil was an empire, its characteristics and when, why and how the independence process took place. The methodology was based on an exploratory bibliographic research which will be explored in books, scientific articles, websites and theses. And the results obtained in this article are learning about the subject, showing what was the Brazil empire, its characteristics, who were the important people of that time and how the process of independence in Brazil took place and its characteristics.

Keywords: Brazil. Empire. Independence.

\section{INTRODUÇÃO}

O Brasil Império foi um período da história brasileira que começou logo depois Independência do Brasil, declarada em 1822, quando D. Pedro I fez o grito da independência, nas margens do rio Ipiranga, na cidade de São Paulo (MACEDO, 2020).

A Independência do Brasil é um dos acontecimentos mais importantes para a história do país. Esse episódio corresponde a quebra de domínio Português sobre a nação, principalmente nas relações econômica e política. De acordo com a história, a 
Independência do Brasil aconteceu no dia 7 de setembro de 1822 , clamada por D. Pedro (Alves,2018).

A Independência do Brasil é um dos fatos históricos mais importantes de nosso país, pois marca o fim do domínio português e a conquista da autonomia política. Muitas tentativas anteriores ocorreram e muitas pessoas morreram na luta por este ideal (RAMOS, 202I).

Neste artigo foi abordado o que foi, quando e como surgiu o Brasil império e como ocorreu o processo de Independência do Brasil e suas fases e também que foram os personagens fundamentais nessa época na história do Brasil.

De acordo com Queiroz ([s.n.]), O Brasil Império (1822-1889) foi um período na história do Brasil de grandes transformações políticas e econômicas. Dividido em três fases, o Primeiro Reinado (I822-I83I), o Período Regencial (I83I-I840) e o Segundo Reinado (I840-1889), concentrou também a formação de instituições importantes, que permanecem até os dias de hoje, como as Forças Armadas e o IHGB, além de projetos de infraestrutura fundamentais para o desenvolvimento econômico já no século XX e todo um imaginário político e simbólico sobre o Brasil enquanto nação.

De acordo com Bezerra ([s.n.]), ocorreu o processo de independência do Brasil também é distinto das demais colônias da América, porque aqui, a Família Real Portuguesa ficou instalada de 1808 a 1820, tornando a luta diferente dos demais territórios.

$\mathrm{O}$ artigo de pesquisa utilizou -se da metodologia caracterizada com pesquisa bibliográfica exploratória onde será explorado em livros, artigos científicos, sites e teses, abordando assuntos como o ocorreu o Brasil império e suas fases e de forma ocorreu o processo de independência do Brasil.

De acordo com Cervo e Bervian (1983) escrevem que a pesquisa bibliográfica explica um problema a partir de referenciais teóricos publicados em documentos". Por esta afirmação é possível inferir então que, quando o pesquisador se propõe a fazer uma pesquisa bibliográfica, está convicto que deverá, com base nessa pesquisa, explicar ou apresentar um resultado para uma determinada situação, que será sua contribuição para a ciência ou área de atuação. 
De acordo com Amaral (2007) a pesquisa bibliográfica é uma etapa fundamental em todo trabalho científico que influenciará todas as etapas de uma pesquisa, na medida em que der o embasamento teórico em que se baseará o trabalho. Consistem no levantamento, seleção, fichamento e arquivamento de informações relacionadas à pesquisa.

\section{BRASIL IMPÉRIO E SUAS FASES}

Segundo Queiroz ([s.n.]), o período do Brasil Império teve início com o processo de Independência do Brasil (I821-1825) e terminou com a Proclamação da República (I889). Em I822, o que era "Reino Unido de Portugal, Brasil e Algarves" tornou-se, oficialmente, "Império do Brasil", o qual estabeleceu como forma de governo uma monarquia constitucional parlamentarista e D. Pedro I como primeiro imperador do Brasil. Tradicionalmente, dividimos o Brasil Império em três fases: Primeiro Reinado (I822-I831), Período Regencial (1831-1840) e Segundo Reinado (1840-1889).

Brasil Imperial é um período da história brasileira entre 7 de setembro de 1822 (Independência do Brasil) e is de novembro de 1889 (Proclamação da República). Neste período, o Brasil foi governado por dois monarcas: D. Pedro I e D. Pedro II (RAMOS, 2007).

As fases que abordamos mais profundamente são primeiro reinado, período regencial e segundo reinado, foi mostrado como ocorreu cada fase com suas próprias características.

O Primeiro Reinado compreendeu o período do dia o7 de setembro de 1822 até o dia 07 de abril de 1831. Nessa fase da monarquia, Dom Pedro I (1798 - 1834), decretou a Independência do Brasil, governou o país como Imperador e abdicou do trono em favor do seu filho Pedro de Alcântara, que posteriormente veio a se tornar o Imperador Dom Pedro II (I825 - I89I). Durante o primeiro reinado, após a definição da autonomia política brasileira, era preciso criar os símbolos nacionais, as instituições e os órgãos administrativos, além de um conjunto de leis para esse estado novo que surgiu. Diante disso, uma das primeiras atitudes tomada por D. Pedro I em seu governo, foi a criação de uma assembleia Constituinte para implementar a Constituição do Brasil Império. No ano de I824, D. Pedro I outorgou a primeira Constituição do Brasil (MACEDO,2019). 
De acordo com Silva ([s.n.]), O Primeiro Reinado (I822-1831) marcou os anos iniciais do Brasil como nação independente após o processo de independência ter sido conduzido por intermédio de D. Pedro I. Com esse acontecimento, o Brasil transformou-se em uma monarquia - a única da América Latina - e foi governada por D. Pedro I de maneira autoritária. Os primeiros dois anos do Brasil como nação independente tiveram como principal debate (além da procura pelo reconhecimento internacional) a elaboração de uma constituição para o país. Esse documento seria elaborado por uma Assembleia constituinte que havia sido escolhida em eleições realizadas após a independência. A constituição elaborada por D. Pedro I e seu conselho foi outorgada, isto é, foi imposta por vontade do imperador no dia 25 de março de 1824 .

De acordo Rosa (2019), Período Regencial foi o momento da História do Brasil entre o Primeiro e o Segundo Reinado. Teve início depois que Dom Pedro I abdicou ao trono (1831) e se entendeu até o denominado Golpe da Maioridade, quando D. Pedro II passou a governar o império. O período é marcado por intensos conflitos político-sociais realizados em todo país e é dividido em Regência Trina Provisória, Trina Permanente, Una do Padre Feijó e Una de Araújo Lima.

O Período Regencial teve início após D. Pedro I abdicar do trono brasileiro em I8zI. Como o filho dele não poderia assumir o trono por ter apenas cinco anos, foi feita uma transição em que o país foi governado por regentes. Nesse período, o Brasil teve uma breve experiência de descentralização que resultou em uma série de rebeliões em diferentes províncias. O Período Regencial brasileiro, como vimos, começou em I83ı e estendeu-se até I840, quando a maioridade de D. Pedro II foi antecipada para que ele assumisse o trono do Brasil. Esse período de nove anos pode ser dividido basicamente em: Regência Trina Provisória (1831); Regência Trina Permanente (I831-I835); Regência Una de Feijó (I8351837); Regência Una de Araújo Lima (I837-1840) (SILVA, [s.n.]).

Segundo Macedo (2019), O Segundo Reinado foi uma época dentro da monarquia em que Dom Pedro II assumiu o poder do país e que durou desde o dia 23 de julho de 1840 até o dia is de novembro de i889. Nesse período, aconteceram várias modificações e revoluções que transformaram a história do Brasil. 
O segundo reinado foi a segunda etapa da monarquia no Brasil, primeiro houve o primeiro reinado onde Dom Pedro I governou o país, logo após veio o período regencial. Eles foram responsabilizados por várias revoltas que ocorreram pelo país a fora naquela época. Foi então que aplicaram o Golpe da Maioridade, uma antecipação da maioridade de Pedro de Alcântara, para que assim, ele pudesse assumir o poder. Depois desse golpe, D. Pedro II assumiu o trono, com apenas is anos de idade, no dia 23 de julho de 1840.

De acordo com os estudos de Silva ([s.n.]), O Segundo Reinado foi o período da história brasileira em que o Brasil foi governado por Dom Pedro II. Esse período iniciou-se com o Golpe da Maioridade, de I840, que antecipou a maioridade de D. Pedro II, permitindo-o assumir o trono com apenas I4 anos. D. Pedro II governou o Brasil até I889 e, em seu reinado, diversas mudanças aconteceram no país. O Golpe da Maioridade consistiu basicamente em uma manobra política para permitir que D. Pedro II assumisse o trono brasileiro com apenas 14 anos (a lei brasileira só permitia com I8 anos), dando início ao Segundo Reinado.

\section{A INDEPENDÊNCIA DO BRASIL E SUAS CAUSAS}

A independência do Brasil foi declarada no dia 7 de setembro de I822, e, com ela, o Brasil determinou o fim do laço colonial que existia com Portugal, declarando-se como uma nação independente. A independência do Brasil foi resultado de uma série de transformações que o país enfrentou a partir do Período Joanino e teve como grandes nomes Pedro de Alcântara e José Bonifácio (SILVA, [s.n.]).

De acordo com o Silva (2021) a independência do Brasil aconteceu em I822, tendo como grande marco o grito da independência que foi realizado por Pedro de Alcântara (D. Pedro I durante o Primeiro Reinado), às margens do Rio Ipiranga, no dia 7 de setembro de 1822. Com a independência do Brasil declarada, o país transformou-se em uma monarquia com a coroação de D. Pedro I.

De acordo com Bezerra (202I) as causas da Independência do Brasil foram várias as causas da Independência do Brasil, que se destaca com desentendimento entre os deputados portugueses e brasileiros nas Cortes de Lisboa, a vontade da elite econômica brasileira em acabar com o monopólio comercial português e as ideias iluministas a respeito da liberdade dos povos. 
De acordo com Macedo,(2021) as causas são que a família real chegou no Brasil durante o Período Napoleônico e após o fim dessa era, no ano de 1815 nos países da Europa, os portugueses fizeram pressão para que o imperador voltasse para casa. No Brasil existia dois movimentos políticos importantes, um era a favor de que houvesse a Revolução Republicana Liberal Abolicionista, o outro era formado por uma elite agrária muito conservadora. $\mathrm{O}$ movimento Republicano e Abolicionista ganhou força por causa da insistência de D. João VI em permanecer no Brasil. A insatisfação com a permanência de D. João VI no Brasil, fizeram com que os portugueses liderassem a Revolução Liberal do Porto no ano de 1820.

A independência do Brasil teve como grande ponto de partida a Revolução Liberal do Porto, que tinha intenções para o Brasil diferentes das que a elite brasileira possuía. Essa divergência de interesses fez com que essa camada social passasse a defender a ideia de ruptura do laço existente com a metrópole. Os fatos que levaram a isso foram a transferência da Corte portuguesa e Período Joanino e a Revolução Liberal do Porto (SILVA, [s.n.]).

\section{O PROCESSO INDEPENDÊNCIA DO BRASIL}

De acordo Silva, (202I) o processo ocorreu durante o Período Joanino, medidas modernizadoras foram implantadas no Brasil. Em I815, o Brasil foi elevado à condição de Reino Unido e, assim, o Brasil deixou de ser colônia. Em I82o, a Revolução Liberal do Porto foi iniciada em Portugal e reivindicava o retorno do rei português. Com o retorno de D. João VI para Portugal, D. Pedro foi colocado como regente do Brasil. As cortes portuguesas exigiam a revogação das medidas implantadas no Brasil e o retorno do príncipe regente. Durante o "Dia do Fico”, D. Pedro declarou que permaneceria no Brasil. No "Cumpra-se", determinou-se que as ordens portuguesas só seriam cumpridas no Brasil com o aval de D. Pedro. O grito da independência - se de fato tiver acontecido - ocorreu nas margens do Rio Ipiranga, no dia 7 de setembro de 1822.

Para Alves (2018), a Família Real chegou no Brasil, no dia 22 de janeiro de 1808 , em Salvador-BA. Ele cumpriu a exigência feita pelos ingleses e estabeleceu o Decreto de Abertura dos Portos do Brasil aos países amigos de Portugal. Foram realizadas inúmeras 
tentativas para que a Independência do Brasil acontecesse de forma rápida. Porém, o feito dos Movimentos Separatistas não consolidou esse evento, mas influenciou na construção de ideais para uma nação emancipada. Um exemplo desse movimento é a Inconfidência Mineira, realizada em 1789. A Independência do Brasil foi declarada por D. Pedro quando ele estava em viagem de Santos para São Paulo. A famosa frase: "Independência ou Morte" foi dita por ele quando estava próximo ao riacho Ipiranga. Por isso, a expressão também é conhecida como "O grito do Ipiranga" cujo foi declamada no dia 7 de setembro de i822. O dia do fico foi um episódio importante para o processo da independência do Brasil. Esse momento corresponde a frase: "Diga ao povo que fico" dita em 1822 por D. Pedro, o regente do Brasil da época. Após o Dia do Fico, em 9 de janeiro de I822, D. Pedro traçou uma série de medidas que mudariam definitivamente a História do Brasil. Convocou uma Assembleia Constituinte, organizou a Marinha de Guerra e obrigou as tropas de Portugal a voltarem para o reino, exigindo que nenhuma lei entraria em vigor sem sua aprovação.

\section{CONSIDERAÇÕES FINAIS}

Através do artigo chegamos na conclusão que o Brasil Império, foi um momento muito importante para história brasileira, mais foi muito conturbado, onde ocorreu como vimos no artigo que começou junto com a indenpência do Brasil pelo Imperador do Brasil Dom Pedro I. Dessa forma tanto o Brasil Império e o processo de Independência começou com a vinda família real para o brasil e dessa maneira passou por muitos conflitos populares, como os movimentos separatistas, com o brasil deixando de ser colônia, assim veio o dia do fico onde Dom Pedro, disse "Se é para o bem de todos e felicidade geral da Nação, estou pronto! Digam ao povo que fico”, por fim quando estava tudo certo com o planejado por Dom Pedro no dia o7 de setembro de 1822 nas margens do rio Ipiranga o imperador do Brasil, proclamou a independência do Brasil dizendo a seguinte frase " Independência ou morte”. Dessa forma conclui-se que a Independência e o Brasil Império sempre caminharam juntas e como muitos conflitos, mas que acabaram sendo a melhores coisas feitas para o Brasil na época até hoje. 


\section{REFERÊNCIAS}

ALVES, Jessica. Independência do Brasil.20I8. Disponível em: < https://www.educamaisbrasil.com.br/enem/historia/independencia-do-brasil > Acesso em: 24.julho.202I.

AMARAL, João J. F. Como fazer uma pesquisa bibliográfica. 2007. Disponível em: $\langle$ http://200.17.137.109:808I/xiscanoe/courses-

I/mentoring/tutoring/Como\%2ofazer\%2opesquisa\%2obibliografica.pdf $>$. Acesso em: 24 . julho.202I.

BEZERRA, Juliana. Independência do Brasil, [s.n.]. Disponível em: < https://www.todamateria.com.br/independencia-do-brasil/ > Acesso em: 27.julho.202I.

BEZERRA, Juliana. Independência do Brasil, 2021. Disponível em: < https://www.todamateria.com.br/independencia-do-brasil/ > Acesso em: o8.agosto.2021. CERVO, Amado Luiz; BERVIAN. Pedro Alcino. Metodologia científica: para uso dos estudantes universitários. São Paulo: McGraw-Hill do Brasil, 1983.

MACEDO, Marcia. Primeiro Reinado,2019. Disponível em:

https://www.educamaisbrasil.com.br/enem/historia/primeiro-reinado> Acesso em: 28. julho.2021.

MACEDO, Marcia. Segundo Reinado,2019. Disponível em: < https://www.educamaisbrasil.com.br/enem/historia/segundo-reinado> Acesso em: 28. julho.2021.

MACEDO, Marcia. Brasil Império, 2020. Disponível em: < https://www.educamaisbrasil.com.br/enem/historia/brasil-imperio> Acesso em: 27 . julho.2021.

MACEDO, Marcia. Causas da independência do Brasil, 2021. Disponível em: < https://www.educamaisbrasil.com.br/enem/historia/causas-da-independencia-do-brasil> Acesso 07. Agosto .2021.

QUEIROZ, Túlio. Brasil Império, [s.n.]. Disponível em:< https://mundoeducacao.uol.com.br/historiadobrasil/brasil-imperio.htm > Acesso em : 27.julho.2021. 
RAMOS, Jefferson Evandro Machado. Brasil Imperial ,2007. Disponível em:< https://www.historiadobrasil.net/imperial/> Acesso em: 27. julho.202I.

RAMOS, Jefferson Evandro Machado. Independência do Brasil,2021. Disponível em:< https://www.suapesquisa.com/independencia/ > Acesso em: 27.julho.2021.

ROSA, Joseane. Período Regencial, 2019. Disponível em:< https://www.educamaisbrasil.com.br/enem/historia/periodo-regencial > Acesso em: 28. julho.2021.

SILVA, Daniel Neves. Independência do Brasil, [s.n.]. Disponível em: < https://www.historiadomundo.com.br/idade-contemporanea/independencia-brasil.htm > Acesso em: 07.agosto.2021.

SILVA, Daniel Neves. Período Regencial, [s.n.]. Disponível em: < https://www.historiadomundo.com.br/idade-contemporanea/periodo-regencial.htm > Acesso em: 28. julho.202I.

SILVA, Daniel Neves. Segundo Reinado (1840-1889), [s.n.]. Disponível em: < https://www.historiadomundo.com.br/idade-contemporanea/segundo-reinado-18401889.htm > Acesso em: 28. julho.2021.

SILVA, Daniel Neves. Independência do Brasil; Brasil Escola. Disponível em: https://brasilescola.uol.com.br/historiab/independencia-brasil.htm. Acesso em o7 de agosto de 2021. 